\title{
Reliability, validity and responsiveness of the Dutch version of the AOSpine PROST (Patient Reported Outcome Spine Trauma)
}

\author{
Said Sadiqi ${ }^{1}$ - Marcel W. Post ${ }^{2,3}$ - Allard J. Hosman ${ }^{4} \cdot$ Marcel F. Dvorak $^{5}$. Jens R. Chapman ${ }^{6} \cdot$ Lorin M. Benneker $^{7}$. \\ Frank Kandziora $^{8} \cdot$ S. Rajasekaran ${ }^{9} \cdot$ Klaus J. Schnake $^{10}$ - Alexander R. Vaccaro ${ }^{11}$ • F. Cumhur Oner ${ }^{12}$
}

Received: 17 November 2019 / Revised: 22 June 2020 / Accepted: 24 July 2020 / Published online: 19 August 2020

(c) The Author(s) 2020

\begin{abstract}
Purpose To validate the Dutch version of AOSpine PROST (Patient Reported Outcome Spine Trauma).

Methods Patients were recruited from two level-1 trauma centers from the Netherlands. Next to the AOSpine PROST, patients also filled out SF-36 for concurrent validity. Descriptive statistics were used to analyze the characteristics. Content validity was assessed by evaluating the number of inapplicable or missing questions. Also floor and ceiling effects were analyzed. Internal consistency was assessed by calculating Cronbach's $\alpha$ and item-total correlation coefficients (itcc). Spearman correlation tests were performed within AOSpine PROST items and in correlation with SF-36. Test-retest reliability was analyzed using Intraclass Correlation Coefficients (ICC). Responsiveness was assessed by calculating effect sizes (ES) and standardized response mean (SRM). Factor analysis was performed to explore any dimensions within AOSpine PROST. Results Out of 179 enrolled patients, $163(91.1 \%)$ were included. Good results were obtained for content validity. No floor or ceiling effects were seen. Internal consistency was excellent (Cronbach's $\alpha=0.96$, itcc 0.50-0.86), with also good Spearman correlations (0.25-0.79). Compared to SF-36, the strongest correlation was seen for physical functioning $(0.79 ; p<.001)$. Also test-retest reliability was excellent $(\mathrm{ICC}=0.92)$. Concerning responsiveness analysis, very good results were seen with $\mathrm{ES}=1.81$ and $\mathrm{SRM}=2.03(p<0.001)$. Factor analysis revealed two possible dimensions (Eigenvalues $>1$ ), explaining $65.4 \%$ of variance.

Conclusions Very satisfactory results were obtained for reliability, validity and responsiveness of the Dutch version of AOSpine PROST. Treating surgeons are encouraged to use this novel and validated tool in clinical setting and research to contribute to evidence-based and patient-centered care.
\end{abstract}

Keywords Spine trauma $\cdot$ Outcome instrument $\cdot$ AOSpine PROST $\cdot$ Patient perspective $\cdot$ Function $\cdot$ Health

Communicated by validation of the AOSpine PROST Dutch

version.

Said Sadiqi

s.sadiqi-3@umcutrecht.nl

1 Department of Orthopaedics, University Medical Center Utrecht, HP G05.228, P.O. Box 85500, 3508GA Utrecht, The Netherlands

2 Rehabilitation Center 'De Hoogstraat', Utrecht, The Netherlands

3 Department of Rehabilitation Medicine, Center for Rehabilitation, University Medical Center Groningen, Groningen, The Netherlands

4 Department of Orthopaedic Surgery, Radboud University Medical Center, Nijmegen, The Netherlands

5 Department of Orthopaedics, University of British Columbia, Vancouver, BC, Canada
6 Swedish Neuroscience Institute, Swedish Medical Center, Seattle, WA, USA

7 Department of Traumatology and Orthopaedic Surgery, Inselspital University of Bern, Bern, Switzerland

8 Center for Spinal Surgery, BGU-Hospital, Frankfurt, Germany

9 Department of Orthopaedic and Spine Surgery, Ganga Hospital, Coimbatore, India

10 Center for Spinal Surgery, Schön Klinik Nürnberg Fürth, Fürth, Germany

11 Department of Orthopaedics, Thomas Jefferson University, Philadelphia, PA, USA

12 Department of Orthopaedics, University Medical Center Utrecht, Utrecht, The Netherlands 


\section{Introduction}

Measurement of the results of interventions on the individuals' health-related quality of life is not only relevant for optimal treatment strategies but also from the standpoint of cost-effectiveness. However, the outcomes of spine trauma patients have traditionally been limited to reporting of mortality and neurologic deficits or expressed with instruments designed for chronic conditions [1-3]. The use of different outcome measures, which were not designed for spine trauma, contributes to the ongoing controversies on the optimal treatment of this specific patient population [4, 5].

To address this void, the AOSpine Knowledge Forum Trauma initiated a project to develop and validate a disease-specific outcome measure for spine trauma patients: the Patient Reported Outcome Spine Trauma (AOSpine PROST). The systematic approach and Core Set development methodology of the International Classification of Functioning, Disability, and Health (ICF) of the World Health Organization (WHO) was used as the basis for the development of the tool $[6,7]$. In a preparatory phase, three studies aimed to identify ICF categories relevant to measure outcomes of traumatic spinal column injuries from different perspectives: research, experts and patients. A fourth study investigated various question and response formats for use in AOSpine PROST. In the next phase, a formal consensus process integrated evidence from the preparatory studies and expert opinion and let to the selection of 25 ICF categories as 'core categories' and the appropriate response scale. Subsequently, a draft Dutch version of the tool was developed by clustering the 25 core ICF categories into 19 items and implementing those into the selected 0-100 Numeric Rating Scale (NRS-101). After pilot testing, a definitive Dutch version to be validated was developed [8]

In the developmental process and initial validation, we sought to focus on patients sustaining injuries to their spinal column and excluded completely paralyzed and polytrauma patients, to identify specific problems related to spine trauma. This study aimed to validate the Dutch version of the AOSpine PROST among traumatic spinal column injury patients. More specifically, the psychometric properties were investigated to assess its reliability, validity and responsiveness.

\section{Materials and Methods}

\section{Target population}

Adult ( $\geq 18$ years) traumatic spinal column injury patients who were capable of understanding and adequately filling out the questionnaires were included. Polytrauma patients (Injury Severity Score (ISS) > 15) and patients with complete paralysis (American Spinal Injury Association (ASIA) impairment grade A or B at discharge or transfer from hospital) were excluded.

\section{Instruments}

For the purpose of concurrent validity, the AOSpine PROST should be compared to a validated outcome instrument designed for patients with traumatic spinal column injuries. However, such instrument is not available. Therefore, a generic health-related quality-of-life (HRQoL) outcome instrument, the Medical Outcomes Study 36-item ShortForm Health Survey (SF-36), was also administered to patients as reference standard.

The AOSpine PROST consists of 19 questions on broad aspects of functioning. (Appendix 1 shows the translated and cross-cultural adapted English version.) Each item has a $0-100$ numeric rating scale, with 0 indicating no function at all and 100 the functional level before trauma. The scale is supported by smileys at both ends of the ruler. The SF-36 includes 36 items measuring 8 health subscales, and is widely used to measure general health status of patients with different diseases [9]. The two summary measures, the physical component summary (PCS) and mental component summary (MCS), are calculated from the 8 health subscales. Scores range from 0 to 100 , with higher scores indicating better health status. The Dutch version of SF-36 has shown good validity results $[10,11]$. These questionnaires (AOSpine PROST and SF-36) along with a limited number of additional questions were administered to the patients as one questionnaire via an online system. The additional questions aimed to explore the presence of irrelevant question in AOSpine PROST, the absence of relevant questions and patients' self-reported degree of recovery.

The health professionals participating in the study were asked to complete background data, consisting of sociodemographic characteristics and trauma-related variables and to make an assessment of patient's degree of recovery based on clinical and radiological assessments (not recovered at all, somewhat-, mainly-, and completely recovered).

\section{Study procedures}

Patients were recruited from two level-1 trauma centers in the Netherlands: University Medical Center, Utrecht (UMCU), and Radboud University Medical Center, Nijmegen (RUMC). The study consisted of two arms: test-retest and responsiveness. For the test-retest part, eligible patients who were seen at the outpatient clinic within 13 months post-trauma were invited to participate while in the responsiveness arm patients were recruited shortly 
Table 1 Socio-demographic and clinical characteristics of the study population ${ }^{\mathrm{a}}$

\begin{tabular}{|c|c|c|c|c|c|c|}
\hline & Overall $(n=163)$ & & RUMC $(n=14)$ & & UMCU $(n=149)$ & \\
\hline Male $(\%)$ & $122(74.8)$ & & 11 (78.6) & & $111(74.5)$ & \\
\hline Female & $41(25.2)$ & & $3(21.4)$ & & $38(25.5)$ & \\
\hline Age, mean $\pm \mathrm{SD}$ (range) in years & $48.7 \pm 17.3(18-82)$ & & $53.4 \pm 14.4(21-71)$ & & $48.3 \pm 17.5(18-82)$ & \\
\hline $\mathrm{BMI}$, mean $\pm \mathrm{SD}$ (range) & $24.5 \pm 3.6(16.1-41.2)$ & & $25.6 \pm 2.8(18.5-29.6)$ & & $24.3 \pm 3.7(16.1-41.2)$ & \\
\hline Cohabiting $(\%)$ & $136(83.4)$ & & $11(78.6)$ & & $125(83.9)$ & \\
\hline Smoking (\%) & $26(16.7)$ & & $6(50.0)$ & & $20(13.9)$ & \\
\hline Years of formal education, mean $\pm \mathrm{SD}$ (range) & $\begin{array}{l}15.5 \pm 4.0 \\
(4-26)\end{array}$ & & $\begin{array}{l}16.9 \pm 4.1 \\
(12-24)\end{array}$ & & $\begin{array}{l}15.4 \pm 4.0 \\
(4-26)\end{array}$ & \\
\hline \multicolumn{7}{|l|}{ Employment (\%) } \\
\hline Employed & $48(29.4)$ & & $10(71.4)$ & & $38(25.5)$ & \\
\hline Student & $14(8.6)$ & & 0 & & $14(9.4)$ & \\
\hline Unemployed (health reason) & $69(42.3)$ & & $3(21.4)$ & & $66(44.3)$ & \\
\hline Unemployed (other reason) & $32(19.6)$ & & $1(7.1)$ & & $31(20.8)$ & \\
\hline \multicolumn{7}{|l|}{ Comorbidities $(\%)$} \\
\hline No medical history & $128(78.5)$ & & $7(50.0)$ & & $121(81.2)$ & \\
\hline $1 \geq$ comorbidities & $35(21.5)$ & & $7(50.0)$ & & $28(18.8)$ & \\
\hline Time after trauma, mean \pm SD (range) in months & $\begin{array}{l}4.3 \pm 3.1 \\
(0-13)\end{array}$ & & $\begin{array}{l}2.8 \pm 0.8 \\
(1-5)\end{array}$ & & $\begin{array}{l}4.4 \pm 3.2 \\
(0-13)\end{array}$ & \\
\hline \multicolumn{7}{|l|}{ Cause of trauma (\%) } \\
\hline Motor vehicle/traffic accident & $49(30.1)$ & & $3(21.4)$ & & $46(30.9)$ & \\
\hline Falling & $70(42.9)$ & & $9(64.3)$ & & $61(40.9)$ & \\
\hline Sports/recreation & $37(22.7)$ & & 0 & & $37(24.8)$ & \\
\hline Violence & $3(1.8)$ & & $1(7.1)$ & & $2(1.3)$ & \\
\hline Suicide attempt & $3(1.8)$ & & $1(7.1)$ & & $2(1.3)$ & \\
\hline Other & $1(0.6)$ & & 0 & & $1(0.7)$ & \\
\hline \multicolumn{7}{|l|}{ Fracture details } \\
\hline \multicolumn{7}{|l|}{ Fracture level (\%) } \\
\hline Total number of fractures & $320(100.0)$ & & $22(100.0)$ & & $298(100.0)$ & \\
\hline Cervical spine (C) & $120(37.5)$ & & $14(63.6)$ & & $106(35.6)$ & \\
\hline Thoracic and lumbar spine (TL) & $200(62.5)$ & & $8(36.4)$ & & $192(64.4)$ & \\
\hline Fracture type $^{b}$ & $C$ & $T L$ & $C$ & $T L$ & $C$ & $T L$ \\
\hline Type $A$ & 39 & 163 & 7 & 8 & 32 & 155 \\
\hline Type $B$ & 43 & 36 & 2 & 0 & 41 & 36 \\
\hline Type $C$ & 8 & 1 & 1 & 0 & 7 & 1 \\
\hline Unclassified & 30 & 0 & 4 & 0 & 26 & 0 \\
\hline Trauma-related injuries (\%) & $76(46.6)$ & & $5(35.7)$ & & $71(47.7)$ & \\
\hline \multicolumn{7}{|l|}{ Treatment $(\%)$} \\
\hline Conservative & $96(58.9)$ & & $10(71.4)$ & & $86(57.7)$ & \\
\hline Surgical & $67(41.1)$ & & $4(28.6)$ & & $63(42.3)$ & \\
\hline \multicolumn{7}{|l|}{ ASIA impairment grade at discharge (\%) } \\
\hline$C$ & $4(2.5)$ & & $2(14.3)$ & & $2(1.3)$ & \\
\hline$D$ & $14(8.6)$ & & $2(14.3)$ & & $12(8.1)$ & \\
\hline$E$ & $145(89.0)$ & & $10(71.4)$ & & $135(90.6)$ & \\
\hline
\end{tabular}

${ }^{a}$ The percentage of each characteristic is based on the available total number of patients for the certain characteristic ${ }^{\mathrm{b}}$ According to the AOSpine Spine Injury Classification Systems

RUMC Radboud University Medical Center, Nijmegen, the Netherlands

$U M C U$ University Medical Center Utrecht, Utrecht, the Netherlands 
Table 2 Mean AOSpine PROST scores relative to the degree of recovery, both as reported by patients and as assessed by clinicians [mean \pm SD (range) ]*

\begin{tabular}{lllll}
\hline & Not recovered at all & Somewhat recovered & $\begin{array}{l}\text { Mainly } \\
\text { recovered }\end{array}$ & $\begin{array}{l}\text { Completely } \\
\text { recovered }\end{array}$ \\
\hline As reported by patients & $n=14$ & $n=75$ & $n=63$ & $n=8$ \\
& $43.8 \pm 14.1(14-64)$ & $59.5 \pm 17.3(27-98)$ & $79.8 \pm 12.6(37-98)$ & $96.6 \pm 2.9(91-100)$ \\
As assessed by clinicians & $n=3$ & $n=46$ & $n=88$ & $n=21$ \\
& $53.9 \pm 8.2(45-60)$ & $55.4 \pm 19.0(14-90)$ & $71.2 \pm 18.5(28-100)$ & $79.5 \pm 15.4(38-99)$ \\
\hline
\end{tabular}

${ }^{*} p<.001$ according to Welch's ANOVA

Table 3 Spearman correlation $\left(r_{\mathrm{s}}\right)$ between AOSpine PROST and SF-36, both for the subscales and summary scales

\begin{tabular}{lll}
\hline & $r_{\mathrm{s}}$ & $P$ value \\
\hline SF-36 subscales & & \\
Physical functioning & 0.79 & $<.001$ \\
Role physical & 0.72 & $<.001$ \\
Bodily pain & 0.69 & $<.001$ \\
General health & 0.58 & $<.001$ \\
Vitality & 0.64 & $<.001$ \\
Social functioning & 0.71 & $<.001$ \\
Role emotional & 0.60 & $<.001$ \\
Mental health & 0.61 & $<.001$ \\
SF-36 component summary & & \\
Physical component summary (PCS) & 0.78 & $<.001$ \\
Mental component summary (MCS) & 0.58 & $<.001$ \\
\hline
\end{tabular}

before discharge from hospital. After informed consent, patients received an email with a link to the questionnaire or postal mail with a login code. For the purpose of test-retest, one week after completion patients were asked to fill out the same questionnaire once more. In the responsiveness arm, the questionnaire was administered three times: at 2-week, 6-week and 3-month post-trauma. If it was not completed within 3 days, patients received a reminder via email or telephone.

\section{Statistical analysis}

Patient characteristics were analyzed using descriptive statistics and frequency analysis. Content validity was assessed by evaluating the number of inapplicable questions and the responses to the open question if any question was missing in AOSpine PROST. Also floor and ceiling effects were analyzed, which could occur if $>15 \%$ of the patients achieve the lowest or highest possible score, respectively. The mean total scores in correspondence to the degree of recovery, both as reported by patients and assessed by the clinicians, were analyzed using Welch's ANOVA.
Concurrent validity between AOSpine PROST and SF-36 was analyzed using Spearman correlation coefficient $\left(r_{\mathrm{s}}\right)$. The $r_{\mathrm{s}}$ can take values from +1 to -1 , with +1 indicating a perfect association, 0 no association and -1 a perfect negative association of ranks [12]. Concurrent validity is supported if the coefficient is at least 0.70 [13].

The internal consistency was assessed by calculating Cronbach's $\alpha$ and item-total correlation coefficients. It is suggested that the value of $\alpha$ should be $>0.70$ for acceptance as satisfactory internal consistency [13, 14]. Also pairwise Spearman correlation was performed to investigate the correlation between AOSpine PROST items.

Test-retest reliability was assessed using Intraclass Correlation Coefficients (ICCs), with good and excellent reliability indicated by values of 0.70 to 0.85 and $>0.85$, respectively [13].

Responsiveness was analyzed using effect size (ES) and standardized response mean (SRM). ES was reflected as the change in score divided by the standard deviation (SD) at 2 weeks. In general, ES $>0.8$ is regarded large based on Cohen's criteria [15]. The SRM is the change score divided by the SD of the change score.

Finally, exploratory factor analysis was performed to identify the dimensionality of the AOSpine PROST. Factors with an Eigenvalue greater than 1 were selected, and selection was confirmed by visual inspection of the scree plot. The factor loading of each item after varimax rotation was examined.

Statistical analyses were conducted using SAS version 9.4 (SAS Institute Inc., Cary, NC, USA).

\section{Results}

\section{Patient characteristics}

Out of 179 patients, a total of $163(91.1 \%)$ were enrolled. Five patients from RUMC and 11 from UMCU were excluded as they did not complete any questionnaire. Out of the included patients, 14 (8.6\%) were from RUMC and 
Table 4 Results for internal consistency and test-retest reliability. Internal consistency for AOSpine PROST items, both item-total correlation (Rho) and Cronbach's $\alpha$ if item removed are shown

\begin{tabular}{lllll}
\hline AOSpine PROST items & $\begin{array}{l}\text { Item-total } \\
\text { correlation }\end{array}$ & $\begin{array}{l}\text { Cronbach's } \alpha \text { if } \\
\text { item deleted }\end{array}$ & ICC & (95\% CI) \\
\hline 1. Household activities & 0.86 & 0.95 & 0.88 & $(0.81-0.92)$ \\
2. Work/study & 0.80 & 0.96 & 0.84 & $(0.71-0.91)$ \\
3. Recreation and leisure & 0.77 & 0.96 & 0.80 & $(0.69-0.87)$ \\
4. Social life & 0.77 & 0.96 & 0.79 & $(0.68-0.87)$ \\
5. Walking & 0.78 & 0.96 & 0.88 & $(0.81-0.92)$ \\
6. Travel & 0.82 & 0.95 & 0.85 & $(0.77-0.91)$ \\
7. Changing posture & 0.84 & 0.95 & 0.70 & $(0.55-0.81)$ \\
8. Maintaining posture & 0.80 & 0.96 & 0.83 & $(0.74-0.89)$ \\
9. Lifting and carrying & 0.81 & 0.95 & 0.78 & $(0.66-0.86)$ \\
10. Personal care & 0.75 & 0.96 & 0.69 & $(0.54-0.80)$ \\
11. Urinating & 0.50 & 0.96 & 0.89 & $(0.83-0.93)$ \\
12. Bowel movement & 0.58 & 0.96 & 0.78 & $(0.66-0.86)$ \\
13. Sexual function & 0.74 & 0.96 & 0.88 & $(0.81-0.93)$ \\
14. Emotional function & 0.62 & 0.96 & 0.70 & $(0.55-0.81)$ \\
15. Energy level & 0.75 & 0.96 & 0.76 & $(0.64-0.85)$ \\
16. Sleep & 0.65 & 0.96 & 0.84 & $(0.75-0.90)$ \\
17. Stiffness of your neck and/or back & 0.66 & 0.96 & 0.78 & $(0.66-0.86)$ \\
18. Loss of strength in your arms and/or legs & 0.66 & 0.96 & 0.78 & $(0.66-0.86)$ \\
19. Back and/or neck pain & 0.62 & 0.96 & 0.55 & $(0.36-0.70)$ \\
\hline
\end{tabular}

Test-retest reliability was analyzed using Intraclass Correlation Coefficient (ICC) along with its 95\% confidence interval $(95 \% \mathrm{CI})$
Table 5 AOSpine PROST scores at 2-week, 6-week and 3-month post-trauma. $(n=59)$

\begin{tabular}{lllll}
\hline Time point & Mean & $\begin{array}{l}\text { Standard } \\
\text { deviation }\end{array}$ & Median $(\mathrm{Q} 1 ;$ Q3) & Range \\
\hline 2 weeks & 44.9 & 15.5 & $43.8(35.9 ; 54.8)$ & $13-100$ \\
6 weeks & 59.8 & 15.1 & $59.2(48.9 ; 71.1)$ & $22-92$ \\
3 months & 72.9 & 15.9 & $74.4(62.6 ; 82.9)$ & $32-99$ \\
\hline
\end{tabular}

149 (91.4\%) from UMCU. The basic patient and clinical characteristics are shown in Table 1.

\section{Content validity}

The mean registered time by the online system to complete AOSpine PROST was 7.0 44.3 (range 1-30) minutes. No item in the questionnaire was indicated as inapplicable or irrelevant.

Eight $(4.9 \%)$ patients reported to have difficulties in filling out AOSpine PROST questions. However, in their clarification patients described in more detail their limitations relevant to a specific question rather than to have a practical difficulty or misunderstanding of the questions. Twentythree $(14.1 \%)$ patients responded positive that a relevant question was missing. A detailed analyses of those responses revealed that no specific question was missing. However, patients did indicate that it was somewhat unclear whether the questions should be solely answered for the spine fracture or also to other sustained fractures.

As no patient had the minimum and only one patient $(0.6 \%)$ the maximum total score, no floor and ceiling effects were observed. AOSpine PROST scores relative to the degree of recovery were more strongly related to the indication by patients $(p<0.001)$ compared to the clinicians' assessments (Table 2).

\section{Concurrent validity}

The Spearman correlations between AOSpine PROST and SF-36 questionnaires are shown in Table 3. The AOSpine PROST most strongly correlated with the physical components $(p<0.001)$ : Physical Functioning $(0.79)$, Role Physical (0.72) and PCS (0.78).

\section{Internal consistency}

The internal consistency of AOSpine PROST total score was excellent (Cronbach's alpha $=0.960)$. With a range of 0.50 to 0.86 item-total correlation showed good results (Table 4). The lowest values were seen for 'Urinating' $(0.50)$ and 'Bowel movement' (0.58). Cronbach's alpha did not improve (0.95-0.96) when an item was removed. As shown 
Table 6 Change in outcome scores (AOSpine PROST and SF-36) from 2 weeks to 3 months with effect size and standardized response mean $(n=59)$

\begin{tabular}{|c|c|c|c|c|c|c|}
\hline Outcome measure & Mean at 2 weeks $(95 \% \mathrm{CI})^{\mathrm{a}}$ & Mean at 3 months $(95 \% \mathrm{CI})^{\mathrm{a}}$ & $\begin{array}{l}\text { Change } 2 \text { weeks to } \\
3 \text { months }(95 \% \mathrm{CI})^{\mathrm{a}}\end{array}$ & $P$ value* & ES & SRM \\
\hline AOSpine PROST & $44.9(40.8 ; 48.9)$ & $72.9(68.7 ; 77.0)$ & $28.0(24.4 ; 31.6)$ & $<.001$ & 1.81 & 2.03 \\
\hline SF-36 PCS & $30.6(28.7 ; 32.6)$ & $41.6(39.4 ; 43.8)$ & $11.0(8.8 ; 13.2)$ & $<.001$ & 1.43 & 1.30 \\
\hline SF-36 MCS & $46.2(42.9 ; 49.6)$ & $45.9(42.3 ; 49.5)$ & $-0.3(-3.2 ; 2.6)$ & 0.834 & -0.02 & -0.03 \\
\hline SF-36 Physical functioning & $30.3(27.9 ; 32.7)$ & $43.2(41.1 ; 45.2)$ & $12.9(10.9 ; 14.8)$ & $<.001$ & 1.39 & 1.72 \\
\hline SF-36 Scale role physical & $25.1(22.6 ; 27.6)$ & $32.4(29.3 ; 35.6)$ & $7.3(3.6 ; 11.1)$ & $<.001$ & 0.76 & 0.51 \\
\hline SF-36 scale bodily pain & $31.5(29.1 ; 33.9)$ & $42.6(39.9 ; 45.3)$ & $11.1(8.6 ; 13.5)$ & $<.001$ & 1.21 & 1.17 \\
\hline SF-36 scale general health & $49.9(47.7 ; 52.2)$ & $49.7(47.2 ; 52.1)$ & $-0.3(-2.5 ; 1.9)$ & 0.795 & -0.03 & -0.03 \\
\hline SF-36 Scale vitality & $46.5(44.1 ; 48.8)$ & $49.8(47.1 ; 52.5)$ & $3.3(1.0 ; 5.6)$ & 0.006 & 0.36 & 0.38 \\
\hline SF-36 scale role emotional & $36.1(31.6 ; 40.7)$ & $37.0(32.9 ; 41.1)$ & $0.9(-2.5 ; 4.2)$ & 0.606 & 0.05 & 0.07 \\
\hline SF-36 social functioning & $34.2(31.1 ; 37.3)$ & $44.1(41.2 ; 47.0)$ & $9.9(6.3 ; 13.5)$ & $<.001$ & 0.84 & 0.72 \\
\hline
\end{tabular}

SF-36 PCS SF-36 Physical component summary (PCS), SF-36 MCS SF-36 Mental component summary (MCS), ES effect size, SRM standardized response mean

${ }^{\mathrm{a}} 95 \%$ confidence interval

${ }^{*} P$ value for change between 2 weeks to 3 months (paired t-test)

Table 7 Changes in AOSpine PROST scores from 2 weeks to 3 months according to patients' self-reported degree of recovery at 3-month follow-up

\begin{tabular}{|c|c|c|c|c|c|c|}
\hline Degree of recovery at 3 months ${ }^{\text {a }}$ & $n$ & Mean at 2 weeks $(95 \% \mathrm{CI})^{\mathrm{b}}$ & Mean at 3 months $(95 \% \mathrm{CI})^{\mathrm{b}}$ & $\begin{array}{l}\text { Change } 2 \text { weeks to } \\
3 \text { months }(95 \% \mathrm{CI})^{\text {b }}\end{array}$ & ES & SRM \\
\hline Not recovered at all/ somewhat recovered & 32 & $42.3(36.4-48.3)$ & $63.9(58.6 ; 69.1)$ & $21.5(17.0 ; 26.1)$ & 1.30 & 1.70 \\
\hline Mainly recovered/ completely recovered & 27 & $47.9(42.4-53.4)$ & $83.5(79.6 ; 87.4)$ & $35.6(31.3 ; 39.9)$ & 2.57 & 3.28 \\
\hline
\end{tabular}

$E S$ effect size, SRM standardized response mean

'The subgroups 'Not recovered at all' and 'Somewhat recovered' as well as 'Mainly recovered' and 'Completely recovered' were combined in order to have a sufficient number of patients for the analysis

${ }^{\mathrm{b}} 95 \%$ confidence interval

in Appendix 2, Spearman correlation between AOSpine PROST items showed also good results (0.25-0.79).

\section{Test-retest reliability}

A total of 64 patients were included in the test-retest arm (Table 4). The mean time after trauma was $5.6 \pm 4.1$ (range $0-13)$ months when completing the first questionnaire. The time between the first and second administrations was $9 \pm 2.3$ (range 4-14) days. Excellent test-retest reliability was seen for the total score ( $\mathrm{ICC}=0.92$ ). When looking into detail per item, all had acceptable to excellent reliability results expect for 'Back and/or neck pain' item ( $\mathrm{ICC}=0.55$ ).

\section{Responsiveness}

Out of initially enrolled 96 patients in the responsiveness arm, $59(61.5 \%)$ had completed the questionnaires at all time points and could be included in the responsiveness analysis. AOSpine PROST mean and median scores for the different time points showed gradual increasing over time
(Table 5), as would be expected with gradual recovery over time. The change in scores from 2 weeks to 3 months are shown in Table 6. The AOSpine PROST scores showed significant $(p<0.001)$ larger changes compared to SF-36. Also, the largest ES and SRM were seen for AOSpine PROST $(\mathrm{ES}=1.81$ and $\mathrm{SRM}=2.03)$. Table 7 shows the changes in AOSpine PROST scores compared to patient-reported degree of recovery; a higher degree of recovery is reflected by a higher change in score with larger ES and SRM.

\section{Factor analysis}

Factor analysis revealed that two factors had an Eigenvalue $>1$, i.e., possible identification of two dimensions across AOSpine PROST items (Factor 1 and Factor 2). These factors had an Eigenvalue of 11.0 and 1.4, and explaining $58.1 \%$ and $7.3 \%$ of the variance, respectively. Rotated factor analysis for the items among those two factors showed that most items load high on Factor 1 and low on Factor 2, indicating that those items considerably contribute to the dimension represented by Factor 1 (see Table 8 and Fig. 1). 
Table 8 Rotated factor analysis for the AOSpine PROST items among the two identified factors (Factor 1 and Factor 2) with Eigenvalue $>1$

\begin{tabular}{lcc}
\hline AOSpine PROST items & Factor 1 & Factor 2 \\
\hline 1. Household activities & 0.82736 & 0.32309 \\
2. Work/study & 0.80518 & 0.25419 \\
3. Recreation and leisure & 0.80928 & 0.18663 \\
4. Social life & 0.65985 & 0.45713 \\
5. Walking & 0.69886 & 0.41582 \\
6. Travel & 0.75397 & 0.38426 \\
7. Changing posture & 0.79559 & 0.34398 \\
8. Maintaining posture & 0.79855 & 0.26865 \\
9. Lifting and carrying & 0.84719 & 0.19205 \\
10. Personal care & 0.60255 & 0.52846 \\
11. Urinating & 0.13289 & 0.87266 \\
12. Bowel movement & 0.19265 & 0.91024 \\
13. Sexual function & 0.58823 & 0.53679 \\
14. Emotional function & 0.49669 & 0.46207 \\
15. Energy level & 0.68449 & 0.37077 \\
16. Sleep & 0.58942 & 0.36121 \\
17. Stiffness of your neck and/or back & 0.74485 & 0.10223 \\
18. Loss of strength in your arms and/or legs & 0.65530 & 0.25290 \\
19. Back and/or neck pain & 0.66564 & 0.15679 \\
\hline
\end{tabular}

Contrarily, the items 'Urinating' and 'Bowel movement' load high on Factor 2 and low on Factor 1. No item loaded low on both factors which indicates that no possible third factor is expected.

\section{Discussion}

This study investigated the psychometric properties of the Dutch language version of the AOSpine PROST (Patient Reported Outcome Spine Trauma), a novel patient-reported outcome measure specifically designed for spine trauma patients. Although a number of outcome instruments have either been developed and validated, or used in, individuals with traumatic spinal cord injury, these tend to focus on the impact of paralysis, e.g., Spinal Cord Independence Measure (SCIM) and Functional Independence Measure (FIM) $[3,16]$. A unique approach in AOSpine PROST is asking patients to recall their pre-injury level of health, more specifically to compare their current function $(0)$ with their pre-trauma level of function (100). This feature might have contributed to the good responsiveness of the tool. Comparing the health and function of spinal trauma patients with normative standardized data is not straightforward because the characteristics of spine trauma patients may very well deviate from those of the general population $[17,18]$. This explains our findings of in general weak correlation between
AOSpine PROST and SF-36. Also, various patient characteristics may influence their outcomes, e.g., cause of trauma and comorbidities.

Excellent results were obtained for internal consistency and test-retest reliability. Very high Cronbach's alpha values were obtained for all items with exception of 'Urinating' and 'Bowel movement.' This is in some contrast with findings from the factor analysis. When applying this to spine trauma patient population, these functions are likely to be adversely affected in spinal cord injured patients [19, 20]. It is hypothesized that this bidimensional model will no longer be applicable when the tool is tested among ASIA A and B patients. As this will be performed in the next phase, it was decided not to make any changes to the current version of AOSpine PROST. Also redundancy of certain items will be investigated in future studies, as well as a detailed analysis per item including larger patients samples. Another interesting finding was the discrepancies in AOSpine PROST scores when related to patient-reported degree of recovery compared to the assessments of the clinicians. This supports the authors' aim to also develop an outcome instrument from the perspective of the treating surgeons: AOSpine CROST (Clinician Reported Outcome Spine Trauma) using the most relevant clinical and radiological parameters [21].

In a preparatory phase of the AOSpine PROST project, a systematic literature review found SF-36 to be the most frequently used generic instrument in studies including spine trauma patients [1]. This finding is supported by several other studies [22-24]. We found good concurrent validity for AOSpine PROST when compared to physical component of SF-36 scores and satisfactory but lower concurrent validity for mental SF-36 scores. This indicates that AOSpine PROST total scores reflect more the patient's experienced physical than the mental health. As was hypothesized further, the responsiveness analysis yielded much better results for AOSpine PROST with the highest ES and SR.

This study has several limitations. The ability to detect minimal clinically important differences has not been investigated completely as a larger patient sample would be required. We certainly aim to investigate this specific aspect in future studies. Second, the contribution of included patients was not equal from the two centers. This was due to the combination of different amounts of spine trauma exposure and practical difficulties in the enrollment process. Finally, somewhat heterogeneous patient population was seen with a relative high mean age and percentage of males. This aging spine trauma patient population is in general seen in the clinics nowadays and also underpinned by various publications $[22,25]$. Also, slight differences were seen between the recruited patients from the two centers. Further investigation of subgroups such as age, specific injuries and severity of spinal cord injury would, however, still be very interesting and will be performed in future studies. 
Fig. 1 Rotated factor pattern of AOSpine PROST factor analysis Each dot with its description represents an AOSpine PROST item: prost_1 $=$ Household activities; prost_2 $=$ Work/ study; prost_3 = Recreation and leisure; prost_4 $=$ Social life; prost_5 = Walking; prost_6 $=$ Travel; prost_7 $=$ Changing posture; prost_ $8=$ Maintaining posture; prost $\_9=$ Lifting and carrying; prost_10 = Personal care; prost_ $11=$ Urinating; prost_12=Bowel movement; prost_13 = Sexual function; prost_14=Emotional function; prost_15=Energy level; prost_16=Sleep; prost_17 $=$ Stiffness of your neck and/or back; prost_18 $=$ Loss of strength in your arms and/or legs; prost_19=Back and/or neck pain

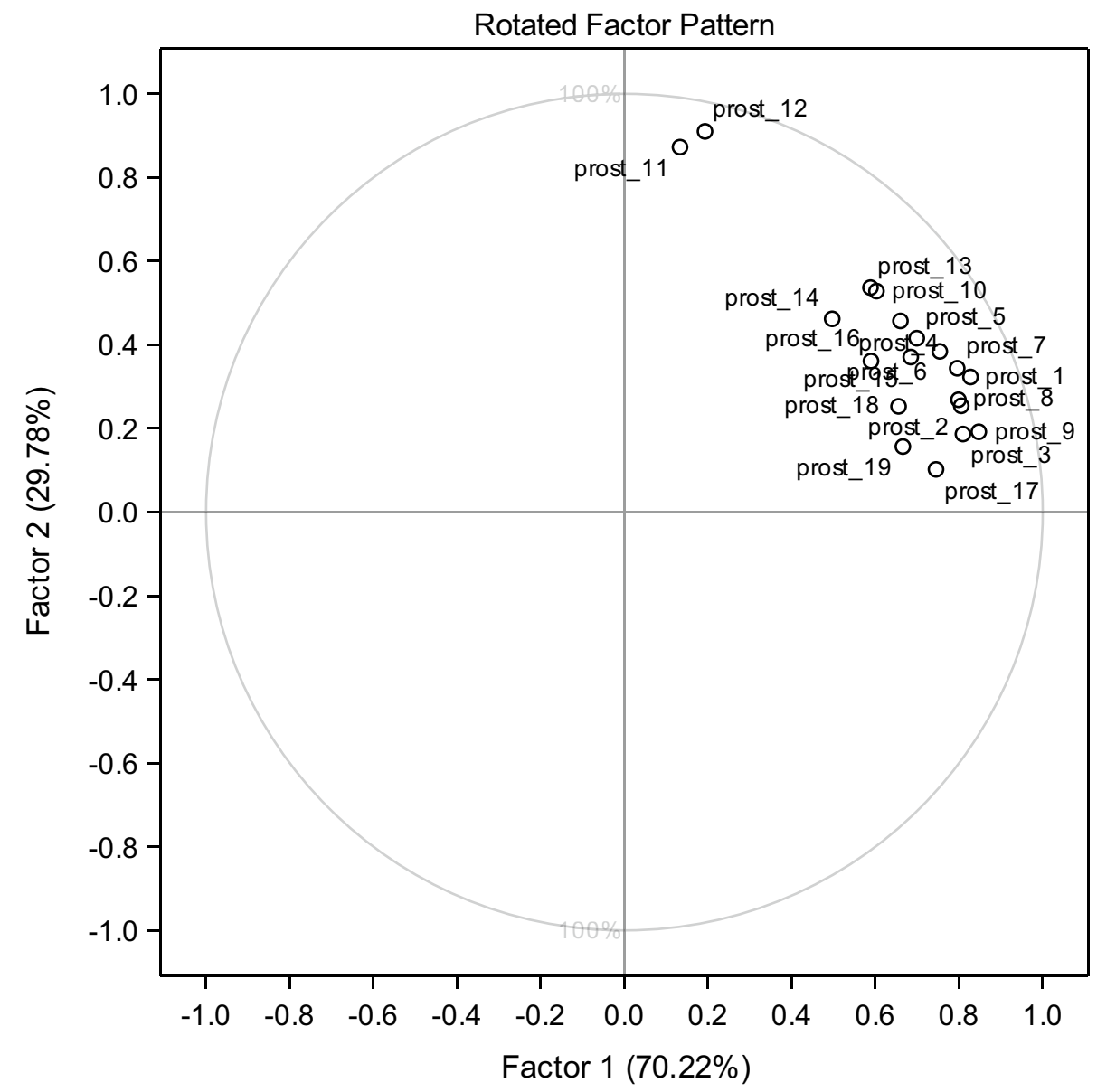

In conclusion, this study aimed to analyze the psychometric properties of the Dutch version of the AOSpine PROST and showed very satisfactory results for reliability, validity and responsiveness. In future studies, the applicability of the tool to complete paralyzed patients will also be investigated. The aim is to translate and cross-cultural adapt the AOSpine PROST into many languages in order to make it available for spine trauma patients around the world. Treating surgeons are encouraged to use this novel and validated tool in clinical setting and research to contribute to further evidence-based and patient-centered spine trauma care.

Acknowledgment The authors thank AOSpine International for their support, and Vicky Kalampoki and Kathrin Espinoza-Rebmann (from AOCID) for their statistical analysis support. Also thanks to Mechteld Lehr and Ruud Hiensch (UMC Utrecht, the Netherlands) as well as Dominique Lamers (Radboud UMC, the Netherlands) for their invaluable support in patient recruitment.

Funding This study was organized and funded by AOSpine through the AOSpine Knowledge Forum Trauma, a focused group of international Trauma experts. AOSpine is a clinical division of the AO Foundation which is an independent medically-guided not-for-profit organization. Study support was provided directly through the AOSpine Research Department.

\section{Compliance with Ethical Statement}

Conflict of interest The authors declare that they have no conflict of interest.

Open Access This article is licensed under a Creative Commons Attribution 4.0 International License, which permits use, sharing, adaptation, distribution and reproduction in any medium or format, as long as you give appropriate credit to the original author(s) and the source, provide a link to the Creative Commons licence, and indicate if changes were made. The images or other third party material in this article are included in the article's Creative Commons licence, unless indicated otherwise in a credit line to the material. If material is not included in the article's Creative Commons licence and your intended use is not permitted by statutory regulation or exceeds the permitted use, you will need to obtain permission directly from the copyright holder. To view a copy of this licence, visit http://creativecommons.org/licenses/by/4.0/. 


\section{Appendix 1. The AOSpine PROST (Patient Reported Outcome Spine Trauma)}

\section{AOSPINE}

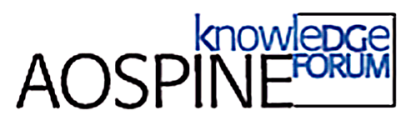

\section{AOSpine PROST (Patient Reported Outcome for Spine Trauma) Your function NOW compared to BEFORE the accident}

This questionnaire contains 19 questions about aspects of your life after the accident that caused your spine injury. Please read the questions and the description of the scale carefully. Please answer ALL questions and answer each question with one cross ( $X$ ") on the scale. This should reflect how you function NOW compared to BEFORE the accident. The scale ranges from 0 to 100 . It is important to realize that $O$ indicates a level at which you are NON-FUNCTIONAL. 100 indicates the level BEFORE the accident, no matter how Patient Name:

Date (MM/DD/YY): 1

Patient ID:

(to be filled in by the health professional) well or poorly you functioned before the accident.

Below is an example.

0. Reading

EXAMPLE

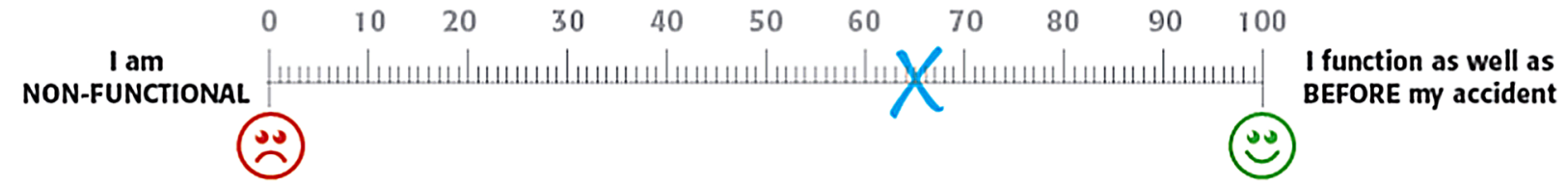

\section{To be completed by the PATIENT}

The questionnaire begins here.

In almost all questions, a number of situations or examples are shown in brackets.

Please base your answer on the situation or example where you are most disabled.

1. Household activities (such as cleaning in and around the house, doing laundry or preparing a meal)

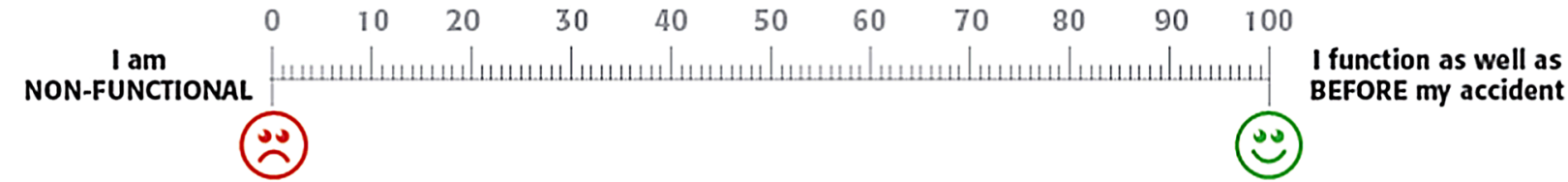

2. Work/study (if you were not working or studying BEFORE the accident, please skip this question)

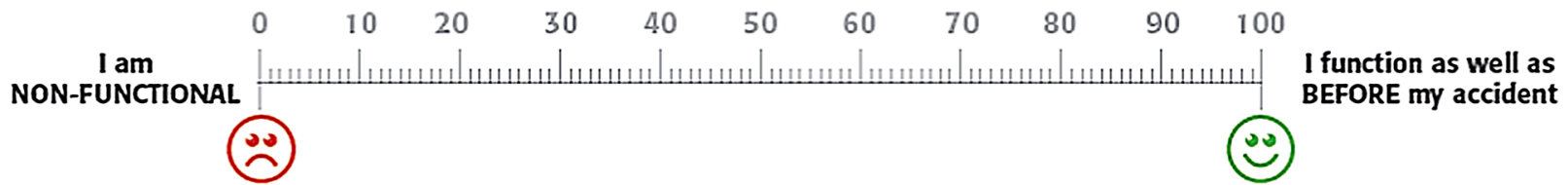

(To be filled out by the health professional)

Study identification code:

Source: Sodiai et al. Dewelopment of the AOSpine Patient Reported Outcome Spine Troums (AOSpine PROST): a universol disease-specific outcome instrument for individuals with traum atic spinal column injury. Eur Spine J 26(5): 1550-1557, 2017. 
3. Recreation and leisure (such as hobbies or sports)

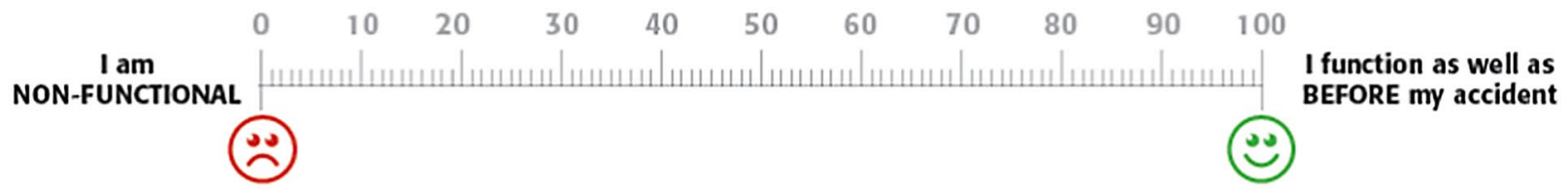

4. Social life (such as maintaining relationships with family, friends and acquaintances)

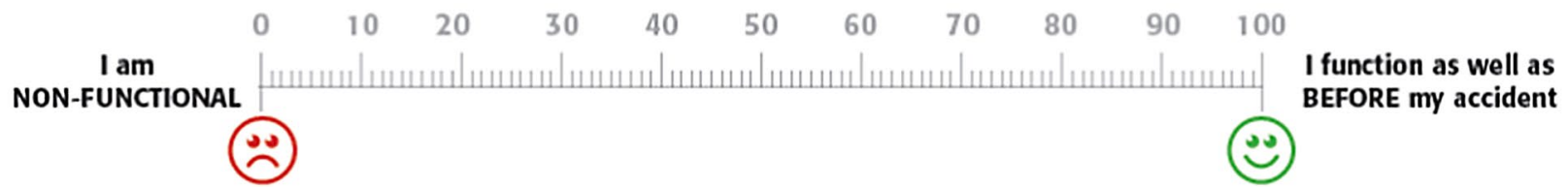

5. Walking (with or without an aid)

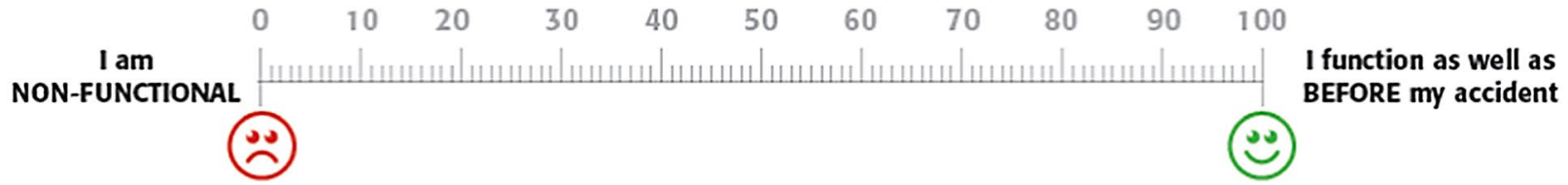

6. Travel (such as driving yourself, using public transportation or other means of transport)

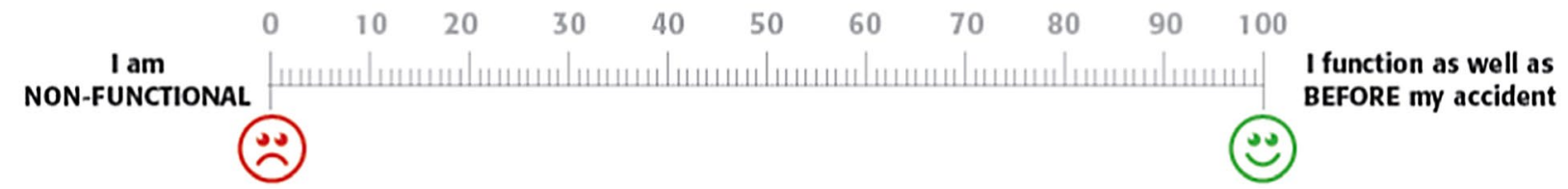

7. Changing posture (such as lying down, sitting or standing)

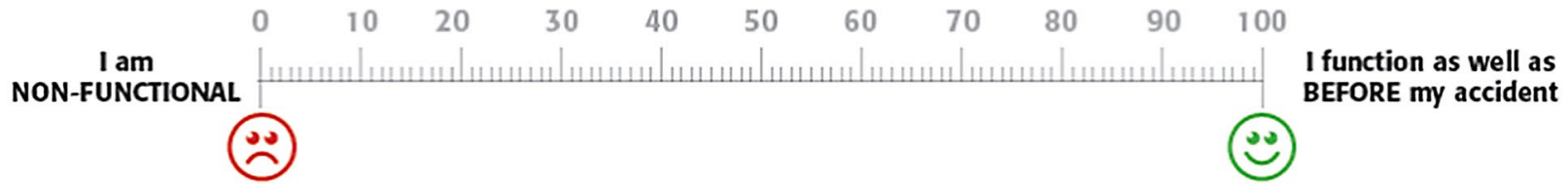

8. Maintaining posture (such as lying down, sitting or standing, for as long as necessary)

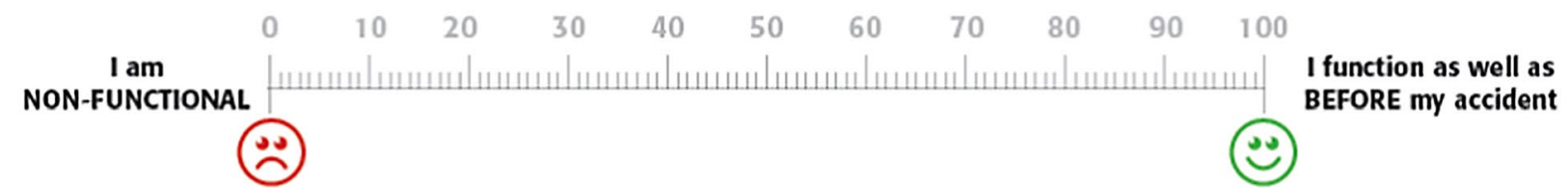

(To be filled out by the health professional)

Study identification code:

CC (2) This work is licensed under the

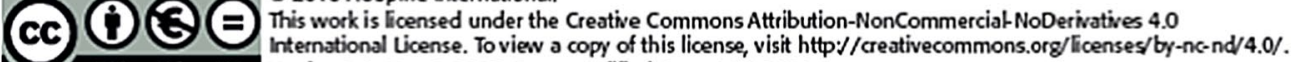

BY NC ND Version 2.0, May 6, 2015. Form modified August 23, 2018. 
9. Lifting and carrying (such as lifting a bag of groceries or carrying a child)

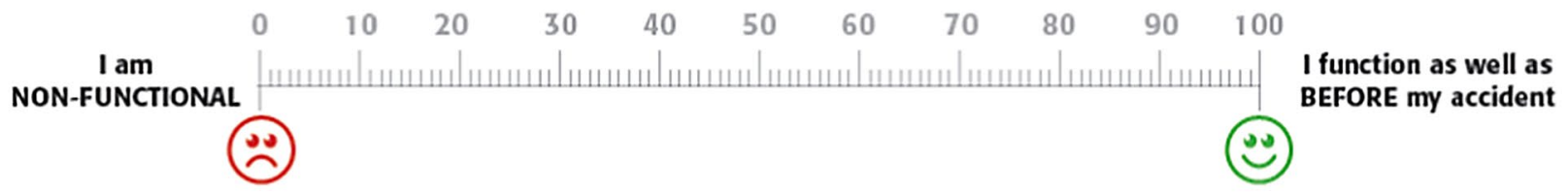

10. Personal care (such as taking a bath or shower, using the toilet or dressing and undressing)

11. Urinating (are you able to urinate; can you hold your urine)

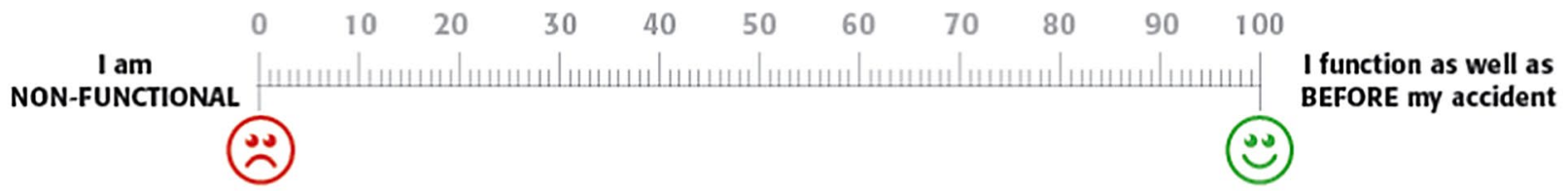

12. Bowel movement (are you able to have a bowel movement; can you hold your bowel movement)

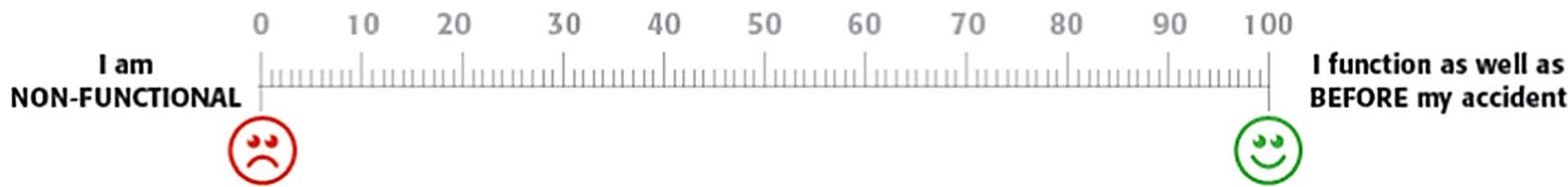

13. Sexual function

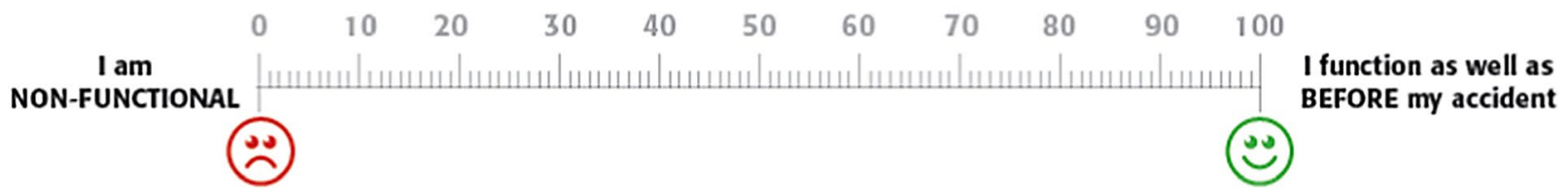

14. Emotional function (such as gloomy, worried or anxious feelings)

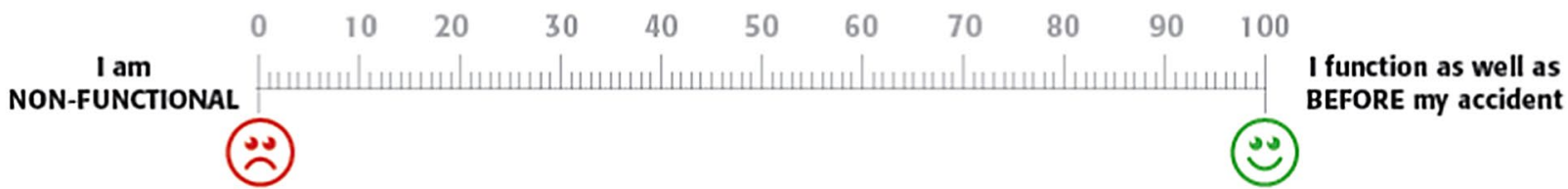

(To be filled out by the health professional)

Study identification code:

Source: Sadiqi et al. Development of the AOSpine Patient Reported Outcome Spine Trauma (AOSpine PROST): a universal

disease-specific outcome instrument for individuals with traumatic spinal column injury. Eur Spine J 26(5): 1550-1557, 2017. 
15. Energy level (such as fatigue or listlessness)

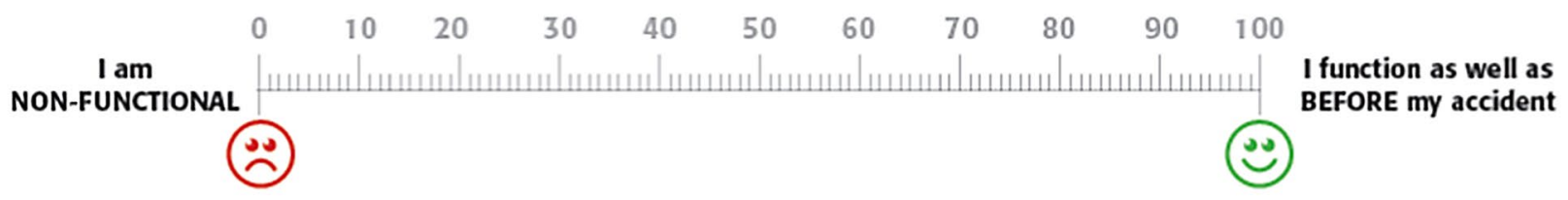

16. Sleep (such as number of hours and quality)

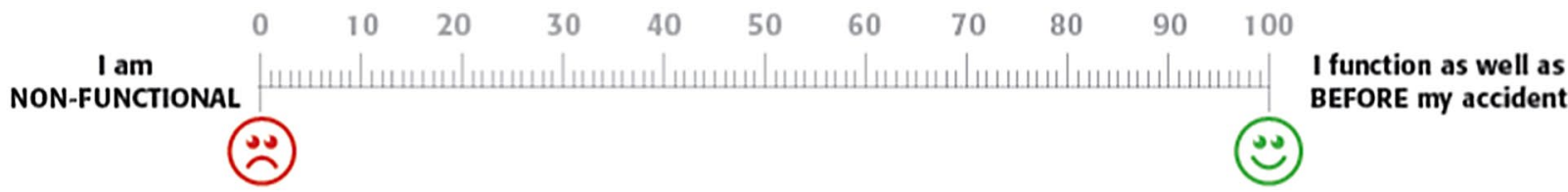

17. Stiffness of your neck and/or back (in terms of disability in overall performance)

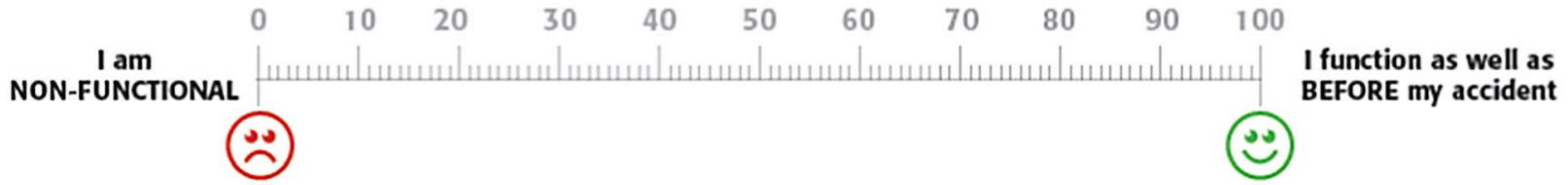

18. Loss of strength in your arms and/or legs (in terms of disability in overall performance)

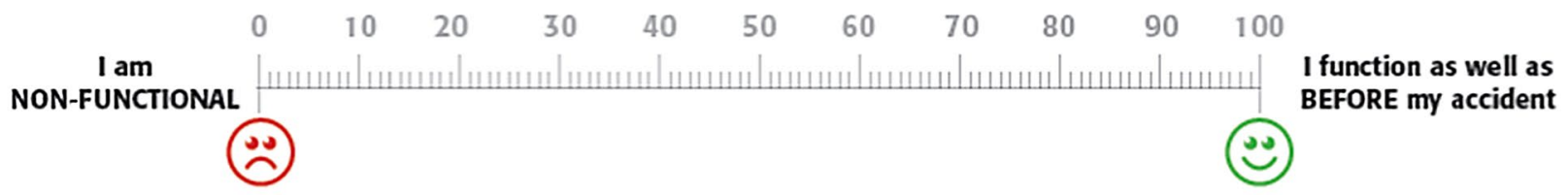

19. Back and/or neck pain (in terms of disability in overall performance)

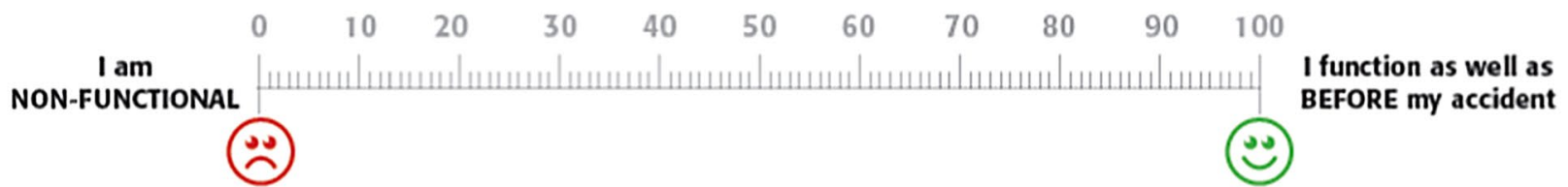

(To be filled out by the health professional)

Study identification code:

Q 2018 AOSpine International.

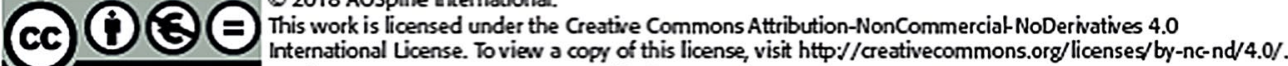

BY NC ND Version 20, May 6, 2015. Form modffied August 23, 2018. 
Appendix 2. Pairwise Spearman correlation between the AOSpine PROST items (for a better overview, correlations $<0.40$ are marked)

\begin{tabular}{|c|c|c|c|c|c|c|c|c|c|c|c|c|c|c|c|c|c|c|}
\hline & Q2 & Q3 & Q4 & Q5 & Q6 & Q7 & Q8 & Q9 & Q10 & Q11 & Q12 & Q13 & Q14 & Q15 & Q16 & Q17 & Q18 & Q19 \\
\hline Q1 & 0.78 & 0.74 & 0.71 & 0.76 & 0.79 & 0.74 & 0.70 & 0.78 & 0.69 & 0.32 & 0.38 & 0.60 & 0.51 & 0.67 & 0.54 & 0.66 & 0.57 & 0.61 \\
\hline Q2 & & 0.76 & 0.70 & 0.64 & 0.73 & 0.65 & 0.65 & 0.66 & 0.65 & 0.29 & 0.36 & 0.53 & 0.52 & 0.68 & 0.59 & 0.57 & 0.59 & 0.51 \\
\hline Q3 & & & 0.63 & 0.64 & 0.70 & 0.68 & 0.66 & 0.79 & 0.63 & 0.28 & 0.33 & 0.57 & 0.50 & 0.65 & 0.52 & 0.60 & 0.54 & 0.50 \\
\hline Q4 & & & & 0.65 & 0.72 & 0.61 & 0.56 & 0.66 & 0.70 & 0.35 & 0.45 & 0.59 & 0.63 & 0.62 & 0.52 & 0.46 & 0.49 & 0.44 \\
\hline Q5 & & & & & 0.72 & 0.67 & 0.64 & 0.66 & 0.69 & 0.42 & 0.47 & 0.60 & 0.48 & 0.59 & 0.48 & 0.54 & 0.55 & 0.52 \\
\hline Q6 & & & & & & 0.76 & 0.70 & 0.73 & 0.71 & 0.31 & 0.37 & 0.59 & 0.54 & 0.64 & 0.57 & 0.58 & 0.51 & 0.55 \\
\hline Q7 & & & & & & & 0.78 & 0.72 & 0.72 & 0.34 & 0.45 & 0.65 & 0.51 & 0.72 & 0.67 & 0.66 & 0.52 & 0.59 \\
\hline Q8 & & & & & & & & 0.70 & 0.61 & 0.31 & 0.44 & 0.53 & 0.48 & 0.63 & 0.58 & 0.61 & 0.51 & 0.60 \\
\hline Q9 & & & & & & & & & 0.66 & 0.25 & 0.35 & 0.61 & 0.50 & 0.65 & 0.51 & 0.61 & 0.59 & 0.59 \\
\hline Q10 & & & & & & & & & & 0.38 & 0.50 & 0.60 & 0.41 & 0.59 & 0.54 & 0.56 & 0.50 & 0.49 \\
\hline Q11 & & & & & & & & & & & 0.77 & 0.39 & 0.37 & 0.34 & 0.32 & 0.30 & 0.36 & 0.25 \\
\hline Q12 & & & & & & & & & & & & 0.47 & 0.44 & 0.40 & 0.48 & 0.31 & 0.42 & 0.29 \\
\hline Q13 & & & & & & & & & & & & & 0.49 & 0.57 & 0.46 & 0.43 & 0.50 & 0.44 \\
\hline Q14 & & & & & & & & & & & & & & 0.61 & 0.54 & 0.40 & 0.47 & 0.45 \\
\hline Q15 & & & & & & & & & & & & & & & 0.68 & 0.56 & 0.56 & 0.55 \\
\hline Q16 & & & & & & & & & & & & & & & & 0.61 & 0.49 & 0.56 \\
\hline Q17 & & & & & & & & & & & & & & & & & 0.53 & 0.65 \\
\hline Q18 & & & & & & & & & & & & & & & & & & 0.58 \\
\hline
\end{tabular}

Q1 = Household activities; Q2=Work/study; Q3 = Recreation and leisure; Q4=Social life; Q5= Walking; Q6=Travel; Q7 =Changing posture; Q8 = Maintaining posture; Q9=Lifting and carrying; Q10= Personal care; Q11 = Urinating; Q12= Bowel movement; Q13=Sexual function; Q14=Emotional function; Q15=Energy level; Q16=Sleep; Q17=Stiffness of your neck and/or back; Q18=Loss of strength in your arms and/ or legs; Q19=Back and/or neck pain

\section{References}

1. Oner FC, Jacobs WC, Lehr AM, Sadiqi S, Post MW, Aarabi B, Chapman JR, Dvorak MF, Fehlings MG, Kandziora F, Rajasekaran S, Vaccaro AR (2016) Toward the development of a universal outcome instrument for Spine Trauma: a systematic review and content comparison of outcome measures used in spine Trauma research using the icf as reference. Spine (Phila Pa 1976) 41:358-367. https://doi.org/10.1097/BRS.0000000000001207

2. Schoenfeld AJ, Wood KB, Fisher CF, Fehlings M, Oner FC, Bouchard K, Arnold P, Vaccaro AR, Sekhorn L, Harris MB, Bono CM (2010) Posttraumatic kyphosis: current state of diagnosis and treatment: results of a multinational survey of spine trauma surgeons. J Spinal Disord Tech 23:e1-8. https://doi.org/10.1097/ BSD.0b013e3181c03517

3. Stadhouder A, Buckens CF, Holtslag HR, Oner FC (2010) Are existing outcome instruments suitable for assessment of spinal trauma patients? J Neurosurg Spine 13:638-647. https://doi. org/10.3171/2010.5.SPINE09128

4. Korovessis P, Baikousis A, Zacharatos S, Petsinis G, Koureas G, Iliopoulos P (2006) Combined anterior plus posterior stabilization versus posterior short-segment instrumentation and fusion for mid-lumbar (L2-L4) burst fractures. Spine (Phila Pa 1976) 31:859-868. https://doi.org/10.1097/01.brs.0000209251.65417.16

5. Wood KB, Li W, Lebl DR, Ploumis A (2014) Management of thoracolumbar spine fractures. Spine J 14:145-164. https://doi. org/10.1016/j.spinee.2012.10.041

6. Selb M, Escorpizo R, Kostanjsek N, Stucki G, Ustun B, Cieza A (2015) A guide on how to develop an international classification of functioning, disability and health core Set. Eur J Phys Rehabil Med 51:105-117

7. World Health Organization (2001) International classification of functioning disability and health: ICF. WHO, Geneva

8. Sadiqi S, Lehr AM, Post MW, Dvorak MF, Kandziora F, Rajasekaran S, Schnake KJ, Vaccaro AR, Oner FC (2016) Development of the AOSpine Patient Reported Outcome Spine Trauma (AOSpine PROST): a universal disease-specific outcome instrument for individuals with traumatic spinal column injury. Eur Spine $\mathrm{J}$ in press

9. Ware JE Jr, Sherbourne CD (1992) The MOS 36-item short-form health survey (SF-36). I. Conceptual framework and item selection. Med Care 30:473-483

10. Aaronson NK, Muller M, Cohen PD, Essink-Bot ML, Fekkes M, Sanderman R, Sprangers MA, te Velde A, Verrips E (1998) Translation, validation, and norming of the Dutch language version of the SF-36 Health Survey in community and chronic disease populations. J Clin Epidemiol 51:1055-1068. https://doi.org/10.1016/ s0895-4356(98)00097-3

11. van Leeuwen CM, van der Woude LH, Post MW (2012) Validity of the mental health subscale of the SF-36 in persons with spinal cord injury. Spinal Cord 50:707-710. https://doi.org/10.1038/ sc. 2012.33

12. Mukaka MM (2012) Statistics corner: a guide to appropriate use of correlation coefficient in medical research. Malawi Med J 24:69-71

13. Terwee CB, Bot SDM, de BoerWindtKnol MRDADL, Dekker J, Bouter LM, Vet HC (2007) Quality criteria were proposed for measurement properties of health status questionnaires. J Clin Epidemiol 60:34-42 
14. Streiner DL, Norman GR (2008) Health measurement scales: a practical guide to their development and use. OUP Oxford, Oxford

15. Cohen J (1992) A power primer. Psychol Bull 112:155-159. https ://doi.org/10.1037//0033-2909.112.1.155

16. Schoenfeld AJ, Bono CM (2011) Measuring spine fracture outcomes: common scales and checklists. Injury 42:265-270

17. Watson WL, Ozanne-Smith J, Richardson J (2007) Retrospective baseline measurement of self-reported health status and healthrelated quality of life versus population norms in the evaluation of post-injury losses. Inj Prev 13:45-50

18. Wilson R, Derrett S, Hansen P, Langley J (2012) Retrospective evaluation versus population norms for the measurement of baseline health status. Health Qual Life Outcomes 10:68

19. Benevento BT, Sipski ML (2002) Neurogenic bladder, neurogenic bowel, and sexual dysfunction in people with spinal cord injury. Phys Ther 82:601-612

20. Branco F, Cardenas DD, Svircev JN (2007) Spinal cord injury: a comprehensive review. Phys Med Rehabil Clin N Am 18(651679):v. https://doi.org/10.1016/j.pmr.2007.07.010

21. Sadiqi S, Verlaan JJ, Mechteld Lehr A, Dvorak MF, Kandziora F, Rajasekaran S, Schnake KJ, Vaccaro AR, Oner FC (2016) Universal disease-specific outcome instruments for spine trauma: a global perspective on relevant parameters to evaluate clinical and functional outcomes of thoracic and lumbar spine trauma patients. Eur Spine J. https://doi.org/10.1007/s00586-016-4596-z

22. Fisher CG, Noonan VK, Dvorak MF (2006) Changing face of spine trauma care in North America. Spine (Phila Pa 1976) 31:S28. https://doi.org/10.1097/01.brs.0000217948.02567.3adiscussion S36

23. Dvorak MF, Johnson MG, Boyd M, Johnson G, Kwon BK, Fisher CG (2005) Long-term health-related quality of life outcomes following Jefferson-type burst fractures of the atlas. J Neurosurg Spine 2:411-417. https://doi.org/10.3171/spi.2005.2.4.0411

24. Fisher CG, Noonan VK, Smith DE, Wing PC, Dvorak MF, Kwon BK (2005) Motor recovery, functional status, and health-related quality of life in patients with complete spinal cord injuries. Spine (Phila Pa 1976) 30:2200-2207. https://doi.org/10.1097/01. brs.0000181058.06412.a9

25. Oner C, Rajasekaran S, Chapman JR, Fehlings MG, Vaccaro AR, Schroeder GD, Sadiqi S, Harrop J (2017) Spine Trauma-what are the current Controversies? J Orthop Trauma 31(Suppl 4):S1-S6. https://doi.org/10.1097/BOT.0000000000000950

Publisher's Note Springer Nature remains neutral with regard to jurisdictional claims in published maps and institutional affiliations. 